\title{
ATENUAÇÃO PRAGMÁTICA E PROBLEMAS DE INTERCOMPREENSÃO: UM ESTUDO INTERCULTURAL ENTRE UNIVERSITÁRIOS PAULISTANOS E CORDOBESES
}

\author{
ATENUACIÓN PRAGMÁTICA Y PROBLEMAS DE INTERCOMPRENSIÓN: UN ESTUDO \\ INTERCULTURAL ENTRE UNIVERSITARIOS PAULISTANOS Y CORDOBESES \\ PRAGMATIC MITIGATION AND INTERCOMPREHENSION \\ PROBLEMS: AN INTERCULTURAL STUDY WITH UNIVERSITY STUDENTS FROM \\ SÃO PAULO AND CÓRDOBA CITY
}

\author{
Ramiro Carlos Humberto Caggiano Blanco \\ Universidade de São Paulo (USP) \\ ramiro.caggiano@usp.br
}

Recibido: 20/12/2016

Aceptado: 17/06/2017

\section{Resumen}

Se expondrán los resultados de una investigación intercultural con estudiantes universitarios de San Pablo (Brasil) y Córdoba (Argentina) en el cual se comparó las tácticas de atenuación pragmática de actos de habla amenazadores de la imagen. Explicitaremos cómo las diferencias encontradas pueden ser explicadas con los conceptos de sociedades de aproximación y distanciamiento de Haverkate (2004) y Briz (2007). Se verá cómo los procedimientos lingüísticos de atenuación empleados por los estudiantes paulistanos crearon cambios semánticos que originaron problemas de intercomprensión.

PALABRAS CLAVE: pragmática, cortesía, atenuación, interculturalidad.

\begin{abstract}
Resumo
Serão expostos os resultados de uma pesquisa intercultural com estudantes universitários de São Paulo (Brasil) e Córdoba (Argentina) na qual se comparou as táticas de atenuação pragmática de atos de fala ameaçadores da imagem. Explicitaremos como as diferenças encontradas podem ser explicadas com os conceitos de sociedades de aproximação e distanciamento de Haverkate (2004) e Briz (2007). Veremos como os procedimentos linguísticos de atenuação empregados pelos estudantes paulistanos causaram mudanças semânticas que originaram problemas de intercomprensão.

PALABRAS CLAVE: pragmática, cortesía, atenuación, interculturalidad.
\end{abstract}

Para citar este artículo / To cite this article: Caggiano Blanco, Ramiro Carlos Humberto (2018): Atenuação pragmática e problemas de intercompreensão: um estudo intercultural entre universitários paulistanos e cordobeses. García Ramón, Amparo y Soler Bonafont, María Amparo (Eds.): ELUA: Estudios de atenuación en el discurso, Anexo IV, págs. 231-249.

Enlace / Link: http://dx.doi.org/10.14198/ELUA2018.Anexo4.13 


\begin{abstract}
We present the results of an intercultural investigation with university students from São Paulo (Brazil) and Córdoba (Argentina) in which a comparison of the tactics of pragmatic mitigation of face-threatening acts was carried out. We demonstrate how the differences found can be explained based on the concepts of approximation and distancing societies (Haverkate 2004; Briz 2007). We also analyze how the linguistic procedures of mitigation used by the students of São Paulo caused semantic changes that compromised the interpretation made by the students of Cordoba, causing problems of intercomprehension.
\end{abstract}

KEY WORDS: pragmatics, politeness, mitigation, interculturalism.

\title{
1. INTRODUÇÃO
}

Quando tratamos de línguas próximas, como é o caso do espanhol em relação ao português, misturam-se elementos sintáticos ou semânticos de uma língua na produção da outra originando uma interlíngua: o conhecido "portunhol". Mesmo falantes que tenham adquirido amplos conhecimentos da segunda língua muitas vezes, por aplicar automaticamente as pautas culturais da sua língua materna, produzem enunciados estranhos ou inadequados aos padrões da comunidade da língua aprendida. Isto se explica porque, conforme Escandell (2006: 33), os interactantes costumam acreditar que o conhecimento do sistema gramatical e os conteúdos semânticos, assim como os conhecimentos e as crenças acerca do uso da língua são comuns a todos.

Por tal motivo devemos pensar a língua desde um enfoque mais amplo que o gramatical, se faz necessário apropriar-se da dimensão pragmática da linguagem haja vista que, contrariamente ao que acontece com os erros gramaticais, os problemas pragmáticos em falantes com conhecimento da gramática podem não ser percebidos como erros e sim como descortesia ou rudeza. A partir da observação destes problemas, e tendo como pressuposto de que há uma diferença no fazer com as palavras nas diferentes culturas nos processos de produção e decodificação-interpretação, surgiu o seguinte questionamento: até que ponto a atenuação dos enunciados feita por paulistanos interfere na compreensão dos mesmos quando interpretados por falantes de outra sociedade com amplos conhecimentos do português.

Em decorrência desta questão, surgiu a necessidade de um estudo cujo objetivo é comparar o emprego de procedimentos linguísticos de atenuação, na produção de atos de fala não corteses (Haverkate 1994), pontualmente atos diretivos e respostas não preferidas, por falantes das cidades de São Paulo (Brasil) e Córdoba (Argentina); e também, analisar as variações interpretativas que podem sofrer os enunciados dos paulistanos quando interpretados pelos cordobeses. 
Nossa experiência empírica como professor de espanhol em São Paulo, nos levou à hipótese de que os brasileiros utilizam mais elementos atenuadores que os argentinos na formulação de enunciados não corteses e de que nas atividades de imagem (facework) as motivações são diferentes, especialmente na construção da imagem própria.

Também acreditamos que, quando empregadas as mesmas táticas de atenuação pragmática, há uma diferença qualitativa na sua realização, fazendo os enunciados dos paulistanos mais atenuados se comparados com os expressados pelos cordobeses.

\section{BREVES ASPECTOS TEÓRICOS DA PRAGMÁTICA, CORTESIA E ATENUAÇÃO}

Significado é uso, reza o famoso lema do filósofo austríaco Ludwig Wittgenstein, ou seja, um enunciado só pode ser explicado se o relacionarmos com as atividades, ou jogos de linguagem no qual ele é utilizado. Deste modo, segundo observa Levinson (2007: 289), a interpretação de certas expressões linguísticas varia radicalmente conforme seja o contexto de uso em que seja empregada. Diante disto, fica evidente que a linguagem excede o limite da sintaxe e da semântica abrindo-se o caminho para uma nova disciplina: a pragmática, cujo escopo é oferecer as ferramentas teóricas e metodológicas necessárias para poder avançar na descrição das regras e princípios que subjazem ao modo em que os falantes usamos a língua (Escandell 2004).

Continuando com o pensamento da autora citada, o objetivo da pragmática é "tratar de estabelecer com precisão quais fatores determinam sistematicamente o modo" de funcionamento de "nossos intercâmbios comunicativos e tentar estabelecer regularidades e generalizações".

Por sua vez, Briz (2011) aponta que quando falamos negociamos "o acordo", a aceitação do outro e articulamos, ao mesmo tempo, as relações interpessoais e, para tal finalidade, utilizamos estratégias de cortesia. Para ele, "do bom andamento destas (estratégias) depende o êxito da comunicação, a felicidade ou infelicidade dos atos de fala aos quais Austin fazia referência, a eficácia dos mesmos".

Como actividad social [la cortesía], en nuestra opinión, se trata de un fenómeno de acercamiento o aproximación al otro, en busca de un equilibrio, un equilibrio social, ya se entienda con relación a la imagen del hablante y del oyente, en los términos de Goffman, Brown y Levinson y Diana Bravo, con los costes y los beneficios que éstos van a lograr o a sufrir, siguiendo las tesis de Leech, o con los derechos y obligaciones de ambos según Fraser, Haverkate, etc. (Briz 2011)

Ampliando esta ideia, o mesmo autor (2004: 71) destaca que as intervenções corteses estão convencionalizadas culturalmente, em outras palavras, cada cultura "subjetiviza de manera frecuente el uso de ciertos mecanismos lingüísticos para mitigar, restar fuerza ilocutiva, que quedan de ese modo codificados para la expresión de la cortesía en dicha lengua".

Ainda, um outro aspecto importante da cortesia a destacar é a sua distinção. Conforme Albelda Marco (2005: 581), desde que Brown e Levinson (1987 [1978]) caracterizaram a cortesia como reparadora dos atos ameaçadores da imagem, os face threatening acts (FTAs), assume-se tacitamente uma correspondência entre o fenômeno da cortesia e atenuação. Porém, Kerbrat-Orecchioni entende a cortesia não só como mitigação dos enunciados, quando 
as imagens estão em perigo, e propõe, em consequência, outra categoria de atos que realçam a imagem do interlocutor. Estes atos introduzidos pela autora, contrariamente ao que acontece com os FTAs, têm prioritariamente a tendência a serem "reforçados" (2014: 49). A estes atos dá o nome de face flattering acts (FFAs) ou atos que reforçam a imagem do interlocutor, tais como os elogios, as felicitações, os apoios na atividade comunicativa, etc.

Em idêntico sentido, Albelda e Briz (2010: 268) salientam que seria mais pertinente falar em cortesia mitigadora, quando existe uma ameaça nos termos apresentados por Brown e Levinson, e uma cortesia valorizadora, que procura "criar ou potenciar um efeito agradável na interação" sem que exista uma ameaça à imagem. Esta última se veicularia tanto por elogios, como sugerido por Kerbrat-Orecchioni, quanto por intensificação com finalidade cortês (Albelda 2005: 583).

Quanto à cortesia atenuadora, Briz esclarece que ela tem o objetivo de dar efetividade ao discurso de forma intencional e estratégica tornando-se compreensível somente pelo seu contexto. É estratégica uma vez que tenta minimizar ou mitigar a ação e intenção ou o efeito que estas (ação e intenção) possam ter ou haver tido na interação (2014: 85). O intuito desta mitigação é o de preservar as relações entre os interlocutores, de "conseguir o acordo ou a aceitação do outro” inclusive, quando seja esta apenas uma aceitação social (Briz 2013). Segundo este autor, pode-se atenuar utilizando recursos morfológicos, sintáticos, léxicos e fonéticos e, com frequência, combinando vários deles. No entanto, pensando na eficácia comunicativa, a atenuação "não pode ser analisada somente a partir de suas funções semânticas" (ou dos recursos morfológicos, sintáticos, lexicais, etc. empregados), mas sim, a partir de princípios pragmáticos, observando-se o papel que desempenham na interação coloquial, já que manipulam o conteúdo, suavizando-o, sempre perseguindo as diferentes finalidades apontadas. Como fenômeno pragmático, a atenuação é um fenômeno contextual (Briz 2014: 91), uma atividade que visa minimizar "o que é dito" e/ou o "ponto de vista" do falante, isto é, "o enunciado e a enunciação, o dito e o dizer" (Albelda y Briz 2010: 245).

Desde o ponto de vista sociocultural, faz-se necessário destacar que, embora a cortesia seja uma atividade universal, cada cultura a subjetiviza de distinta maneira. Como afirmam Albelda e Briz (2010:248) o "sentimento de ameaça à imagem se percebe de diferente modo" por pessoas em diferentes países. Além disso, conforme esta percepção, também têm influência outros elementos socioculturais tais como a idade, o gênero dos interactantes, etc. Dentro desta diferenciação, primeiro Haverkate (2004) e depois Briz (2007), apontaram a distinção entre culturas de aproximação e de distanciamento. Como os autores previnem, não se trata de um par dicotômico mas de um continuum com múltiplos valores intermediários. Deste modo, em algumas sociedades a tendência é mostrar aproximação social, encurtando os espaços interpessoais; interferir na vida privada dos outros e estabelecer pontes de relação e confiança entre os interlocutores (Albelda y Briz 2010: 248), são as culturas de aproximação, na classificação proposta. Por outro lado, outras culturas, que os autores denominam de distanciamento, têm preferência por respeitar o espaço e o âmbito pessoal dos outros e por manter a deferência e precaução nas relações sociais, etc.

Para um reconhecimento eficaz do tipo de cultura, de distanciamento ou de aproximação, Albelda e Briz propõem observar a presença de atenuadores verbais e de cortesia, uma vez que estes constituem um índice da existência de distância social entre os interlocutores. Sendo assim, a atenuação é empregada estrategicamente para compensar tal distância (2010: 249). 
Ainda segundo esses autores (2010: 249-250), as culturas de aproximação favorecem a menor frequência de atenuadores devido à existência de uma menor sensibilidade perante o conceito de ameaças à imagem. Pelo contrário, as culturas de maior distanciamento são propensas a um uso mais acentuado de atenuação. Do mesmo modo, uma cultura de distanciamento não favorece o uso de cortesia valorizadora, enquanto que numa cultura de aproximação os elogios e as intervenções colaborativas que apoiam o que é dito pelos outros, etc. são muito bem vistas.

Finalmente, apesar dos vários elementos existentes para a caracterização de uma cultura como sendo de aproximação ou de distanciamento, coincidimos com os autores na importância do estudo da atenuação pragmática como dado linguístico claro e suficiente para a identificação de uma e de outra. Estes conceitos são relevantes para a análise que apresentaremos.

Nossa pesquisa intercultural foi embasada no projeto ES.POR.ATENUACIÓN, o qual estabelece as bases teóricas metodológicas comuns para à análise e estudos contrastivos, intra e interlinguísticos, da atenuação pragmática nas diferentes normas regionais do espanhol e do português, tanto a partir do ponto de vista sociolinguístico quanto pragmalinguístico (Briz 2013: 302). Esta proposta possibilita a análise quantitativa e qualitativa e, em última instância, a interpretação que façam os interlocutores (Briz 2014: 91).

Nesse sentido, Briz (2013) previne que, ainda que exista acordo quanto ao conceito de atenuação, nem sempre há coincidências no reconhecimento do aspecto atenuador de um elemento porque, como fenômeno pragmático, a atenuação é um fenômeno contextual, motivo pelo qual será necessário precisar o contexto geral e o contexto especifico em que a atividade atenuadora se desenvolve. Consequentemente, para decidir se um procedimento linguístico tem função atenuadora temos que acudir às variáveis situacionais que aportam valiosa informação das circunstancia sociais e comunicativas que favorecem seu emprego (Albelda et alii 2014: 36). Na descrição do contexto geral se elencam os aspectos relacionados à temática da interação; a idade, sexo, nível de instrução, relação vivencial (amigos, colegas de trabalho + conhecidos, etc.), e a relação social e funcional entre interlocutores. Quanto ao contexto específico da interação, ele refere ao momento ou momentos pontuais de fala em uma interação que afetam, favorecem ou determinam os usos e estratégias linguísticas. Esta noção de contexto dinamiza, portanto, o conceito mais geral de situação de comunicação e explica a atividade linguística em um contexto preciso. Desse modo, se faz necessário, para o reconhecimento e explicação da atividade atenuadora, identificar "o que desencadeia ou causa" a atenuação (pode ser um ato anterior -ou algo dentro deste- ou outra intervenção, ou o contexto explícito ou implícito). Faz-se necessário também especificar qual é o membro do discurso afetado/atenuado (o membro do discurso afetado pela atenuação) e qual meio ou meios empregados para atenuar (os recursos ou táticas para conseguir a mitigação), bem como o efeito que, às vezes, produz. A análise destes elementos, "fornece ao analista um critério [...] mais sólido para o seu reconhecimento" (Albelda et alii 2014: 34).

Quanto às possíveis funções pragmáticas da atenuação, Albelda et alii (2014) apontam que podem servir para três fins: 1. Zelar por si próprio autoprotegendo-se pelo expresso ou pelo feito (salvaguarda do eu, autoproteção com imagem), com o intuito de ganhar ou não perder imagem. (Autoproteger-se); 2. Prevenir uma possível ameaça à imagem do outro ou um possível obstáculo para alcançar uma meta (salvaguarda do eu-tu); e 3. Reparar uma ameaça à imagem do outro ou uma intromissão no território do outro [salvaguarda do eu-tu]. 
Como apontam Albelda et alii, após efetuar o reconhecimento da função que cumpre uma forma ou expressão linguística, é conveniente especificar o tipo de procedimento empregado na atenuação. Trata-se das denominadas táticas ou procedimentos de atenuação, que podem consistir em recursos verbais (ou não verbais) na utilização de determinadas formas linguísticas. Podem ser tanto morfológicas ou léxicais (quantificadores, sufixos diminutivos, locuções, etc.) quanto sintáticas (construções complexas, complementos ou atos de fala que sevem à atenuação) (Albelda et alii 2014: 20). Com a finalidade de facilitar a leitura deste artigo, apontaremos os procedimentos de atenuação empregados em nossa pesquisa intercultural. São eles: modificadores morfológicos internos: sufixos diminutivos; modificadores externos: quantificadores minimizadores, aproximativos ou difusores significativos proposicionais ou extraproposicionais; termos ou expressões mais suaves no conteúdo significativo; usos modalizadores dos tempos verbais; verbos, construções verbais, e partículas discursivas com valor modal que expressam opiniões em forma de dúvida ou de probabilidade; construções limitadoras da opinião à própria pessoa; petições, perguntas, mandatos ou ordens expressados de forma indireta; expressões de desculpas; estruturas sintáticas que restringem o ato de fala; partículas e construções justificadoras ou de desculpa; impessoalizações; concessividade; marcadores discursivo modais de objetivação; partículas discursivas e expressões de controle de contato com o interlocutor; uso de formas de tratamento e fórmulas apelativas; e outros procedimentos atenuadores não mencionados anteriormente, entre os quais destacamos o emprego de ironia, humor, anticortesía e oferecimentos de recompensa.

\section{APRESENTAÇÃO DO CORPUS E ANÁLISE}

A pesquisa que embasa este artigo descreve e analisa as relações de comparação entre os procedimentos linguísticos empregados para atenuar enunciados de estudantes universitários da cidade de Córdoba (Argentina) e São Paulo (Brasil), usando o método analítico comparativo com análises qualitativas e quantitativas. Para facilitar as comparações, dadas as características de nossos corpora, realizamos adaptações da metodologia proposta pelo projeto ES.POR.ATENUACIÓN. Dentro destas modificações, talvez a mais importante seja a substituição da ficha de análise do projeto por agrupamentos dos enunciados com fins comparativos, segundo o critério do emprego das táticas de atenuação sistematizadas pelo projeto, com o objetivo de contrastar as semelhanças e diferenças de uso. Assim conseguimos aprimorar a análise quantitativa com o intuito de estabelecer relações entre o maior ou menor número de táticas para mitigar usadas pelos informantes de ambas as cidades. A análise qualitativa, por sua vez, auxiliou na categorização dos procedimentos atenuadores (interpretação de cada uma das estratégias: classificação, tipo, motivação, etc.) e permitiu precisar relações entre as ditas estratégias e as atividades de imagem, à luz dos conceitos de comunidades de fala de proximidade e distanciamento.

Participaram da pesquisa 30 alunos universitários da cidade de São Paulo, (da FMU dos cursos de Letras e de Artes) e 60 alunos universitários do Professorado da Faculdade de Letras da Universidade Nacional de Córdoba. Para a obtenção dos corpora, resumidamente, foram elaborados dois questionários iguais, em português e espanhol, para serem preenchidos por 30 alunos de cada faculdade, mediante a técnica elaborada pelo EDICE chamada "testes de hábitos sociais". Também realizamos um terceiro questionário de interpretação, só para 30 alunos de Córdoba. 
O primeiro passo foi solicitar aos 30 alunos universitários de São Paulo que formulassem enunciados conforme as situações quotidianas do trabalho e da faculdade apresentadas no questionário. Posicionados imaginariamente em cada um desses ambientes, teriam que responder a subordinados imediatos (questão 1: como um líder de grupo de estudo; e questão 4: como um chefe), a colegas, em plano de igualdade (questões 2 e 5), e a superiores imediatos (questão 3: dirigir-se ao professor; e questão 6: ao chefe). Desta forma seriam compreendidas as três variáveis situacionais referentes aos papéis funcionais e sociais dos interlocutores, que se correspondem com a variável poder relativo na teoria de Brown e Levinson (Escandell 2006: 154), em cada um dos ambientes descritos. O questionário continha as seguintes situações:

1) Você está no comando de uma equipe de estudo que tem que preparar um seminário, mas um/a dos/das integrantes não está fazendo a parte dele. Que diz para ele? Quais palavras utilizaria exatamente?

2) Você emprestou dinheiro a um/uma colega já faz um tempo e ele não devolve. Agora você quer que ele (ou ela) o devolva. Que diz a ele/ela? Quais palavras utilizaria exatamente?

3) Um/a ex-professor/a quer emprestado um livro seu. Você não quer emprestar porque ganhou de alguém muito especial Que diz para ele/ela? Quais palavras utilizaria exatamente?

5) Você é o chefe de departamento e tem que comunicar a um empregado o seguinte: $O$ relatório mensal está mal feito, tem que refazê-lo. Quais palavras utilizaria exatamente?

6) Um colega de trabalho com o qual tem muita afinidade o convida para o seu casamento e não irá porque não é o seu desejo. Que diz a ele? Quais palavras utilizaria exatamente?

7) Seu chefe, sabedor de que você não tem compromisso para o próximo feriado, pretende que você trabalhe no plantão, mas você sabe que este pedido não procede porque já trabalhou nos últimos feriados. Que diz a ele? Quais palavras utilizaria exatamente?

Igualmente, solicitamos a 30 alunos universitários de Córdoba que preenchessem um questionário igual ao dos alunos brasileiros para, assim, poder comparar as formas de emissão dos enunciados em cada uma das comunidades de fala a respeito do maior ou menor grau de atenuação e as estratégias empregadas em cada um deles.

Com os enunciados obtidos nos 30 questionários dos alunos paulistanos, foram elaborados outros 30 novos questionários, a serem respondidos pelos estudantes universitários de Córdoba, na Argentina, com o fim de que estes os interpretassem. Quando ideamos este questionário, e este passo da pesquisa, estávamos cientes que, como aponta Briz (2003: 32), uma ação atenuada pode diminuir seu potencial argumentativo em maior ou menor medida, de forma sintagmática, segundo haja mais presença de atenuadores no enunciado, ou paradigmática, pela diferença de valor atenuador dos elementos dentro do enunciado. E também que, embora estas gradações de atenuação estejam no próprio sistema linguístico, podem existir variações entre uma e outra língua, e variedades dentro de cada uma dessas línguas. Finalmente, estas escalas podem estar marcadas por fatores extralinguísticos, como nosso conhecimento de mundo e os valores compartilhados pela coletividade (Charadeau 2014: 35).

Com estas bases, foi solicitado aos universitários da cidade de Córdoba que interpretassem os enunciados produzidos pelos estudantes paulistanos e mensurassem sua força ilocucionária, ou seja, "em que sentido deve interpretar-se a proposição" (Escandell 2006: 65) de acordo com a informação pragmática fornecida pelo contexto sociocultural da comunidade 
cordobesa. Desta forma conseguimos medir o maior ou menor distanciamento entre o que foi solicitado comunicar aos alunos de São Paulo e o que efetivamente entenderam os cordobeses.

Nos 30 formulários interpretativos, com as diferentes respostas de cada um dos alunos paulistanos, foram disponibilizadas 4 alternativas de apreciação para cada enunciado em particular, numa escala de maior a menor imposição ou assertividade, segundo o caso, do conteúdo proposicional (Escandell 2006: 67) dos mesmos.

Como forma de nos auxiliar na análise interpretativa dos enunciados, os informantes também foram solicitados a responder as seguintes duas perguntas de caráter geral relacionadas com a cortesia e a atenuação:

8) Ser compreendido claramente e ser cordial seria o ideal mas, às vezes, em situações delicadas, nem sempre isto ocorre. Leia as alternativas e escolha só uma.

口 É melhor ser cordial mesmo correndo o risco de não ser compreendido/a claramente.

$\square$ É melhor ser compreendido/a claramente mesmo correndo o risco de ser rude.

9) Quando transmitimos mensagens desagradáveis que possam afetar outras pessoas, temos uma série de preocupações. Enumere de 1 a 5, em ordem de prioridade (sendo 1 o prioritário) os principais cuidados que devemos tomar, segundo seu entendimento.

Não ferir a outra pessoa;

- Não quebrar as relações (de amizade, companheirismo, etc.);

- Preservar o relacionamento esperando obter benefícios no futuro;

Não parecer mal educada/o;

Medo de que se espalhe que você é grosso/a.

Para ilustrarmos o trabalho realizado na pesquisa, descreveremos a questão de número 5 que trata de atos de fala não corteses no ambiente de trabalho. Neste ponto foi solicitado aos informantes que, colocados na posição de um chefe de departamento, realizassem um ato de fala diretivo em benefício do falante (ou de terceiros), que consistia em solicitar que refizessem um relatório porque estava mal feito.

5) Você é o chefe de departamento e tem que comunicar a um empregado o seguinte: O relatório mensal está mal feito, tem que refazê-lo.

Quais palavras utilizaria exatamente?

Os enunciados estão enquadrados no contexto das relações de trabalho. A relação vivencial entre os interactantes, segundo as alternativas propostas pelo grupo ES.POR.ATENUACIÓN, é de colegas de trabalho + conhecidos existindo entre eles uma relação hierárquica na qual o falante tem uma posição ou status superior ao ouvinte $[\mathrm{F}+\mathrm{O}]$.

Quanto ao contexto específico, o que pode motivar o emprego de atenuação, está constituído pela ameaça à imagem do interlocutor tanto pelo pedido, refazer, quanto pelo motivo, estava mal feito. Desta forma, o que deveria ser atenuado é a força da exortação, para minimizar a invasão do território, como a causa do solicitado já que contraria as expectativas de ter o trabalho reconhecido. Por sua vez, a imagem do falante também pode estar ameaçada ao se apresentar como alguém autoritário. Por este motivo as estratégias de 
atenuação tiveram como finalidade salvaguardar as imagens dos falantes (salvaguarda eu-tu) ao prevenir, principalmente, conflitos por usurpação de territórios ou direitos do outro.

\subsection{Análise comparativa dos procedimentos linguísticos utilizados para atenuar}

A estratégia mais utilizada nos dois corpora para mitigar foi o emprego de eufemismos e modificadores externos aproximativos, como veremos em seguida.

a) Termos ou expressões mais suaves no conteúdo significativo: eufemismos.

Antes de começarmos a análise desta estratégia, salientamos que, para os fins de nosso trabalho, as variantes do verbo performativo rehacer / refazer foram consideradas com o mesmo valor semântico, uma vez que não "suavizariam" o entendimento do ato ilocucionário, em:

\begin{tabular}{|c|c|}
\hline Córdoba: 10 casos & São Paulo: 5 casos \\
\hline 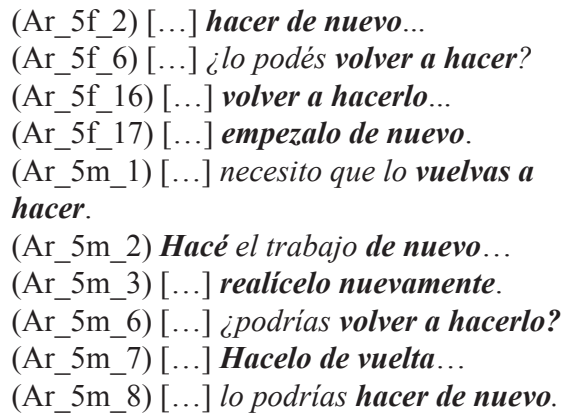 & $\begin{array}{l}(\mathrm{Br} 55 \mathrm{f}-9)[\ldots] \text { Você poderia fazê-lo de novo? } \\
\left(\mathrm{Br} 5 \mathrm{f}_{-} 15\right)[\ldots] \text { fazer melhor } \ldots \\
\left(\mathrm{Br} \_5 \mathrm{~m} \_9\right)[\ldots] \text { precisariam ser reescritos... } \\
\left(\mathrm{Br} 5 \mathrm{~m}_{-} 11\right)[\ldots] \text { você poderia fazer,... } \\
\left(\mathrm{Br} 55 \mathrm{~m}_{-} 15\right)[\ldots] \text { Faça mais caprichado. }\end{array}$ \\
\hline
\end{tabular}

Feita esta ressalva, realizaremos a análise dos eufemismos encontrados na atenuação do núcleo do enunciado, ou seja, aqueles verbos e expressões que expressam o ato ilocucionário de um modo mais ameno, debilitando o significado e minimizando a intenção (Albelda et alii 2014), sempre tomando como referência o verbo performativo rehacer / refazer e suas variantes.

\begin{tabular}{|c|c|}
\hline Córdoba: 4 casos & São Paulo: 5 casos \\
\hline $\begin{array}{l}\left(\mathrm{Ar} 5 \mathrm{f} \_9\right)[\ldots] \text { que lo reveas y corrijas ... } \\
\left(\mathrm{Ar} 5 \mathrm{f} \_12\right)[\ldots] \text { Si lo podés corregir por favor. } \\
\left(\mathrm{Ar} 5 \mathrm{f} \_15\right)[\ldots] \text { Revisalo. } \\
\left(\mathrm{Ar} 5 \mathrm{f} \_19\right)[\ldots] \text { fijate si podés corregirlo. }\end{array}$ & $\begin{array}{l}\text { (Br_5f_1) }[\ldots] \text { gostaria que você passasse a } \\
\text { limpo... } \\
\text { (Br_5f_8) }[\ldots] \text { vamos tentar melhorar cada dia } \\
\text { mais no relatório... } \\
\text { (Br_5f_12) [...] Teria como você arrumá-lo, } \\
\text { porfavor? } \\
\text { (Br_5m_5) }[\ldots] \text { precisamos modificaro } \\
\text { relatório... } \\
\text { (Br_5m_14) }[\ldots] \text { Poderia fazer do jeito... para } \\
\text { tornar mais fácil? }\end{array}$ \\
\hline
\end{tabular}


Embora o número de ocorrência de eufemismos seja quase o mesmo (4 e 5 em cada um dos corpus), podemos apreciar que as cinco formas usadas pelos estudantes de São Paulo, passar a limpo; melhorar; arrumar; modificar e fazer do jeito... para tornar mais fácil, são bem mais "suaves" do que as que empregaram seus pares cordobeses, que se limitaram a trocar rehacer por revisar e corregir (em três ocasiões). Certamente, embora se trate da mesma estratégia de atenuação, os resultados não são os mesmos, já que ao escolher termos mais "comedidos" os enunciados dos universitários paulistanos são bem mais atenuados (variação paradigmática).

b) Modificadores externos: quantificadores minimizadores, aproximativos ou difusores significativos proposicionais ou extraproposicionais

Apontaremos aqui os casos onde a estratégia de atenuação não recai no núcleo ilocucionário do ato de fala senão na causa que o justifica.

\section{Córdoba}

\begin{tabular}{|l|l|}
\hline 1) & $\begin{array}{l}\text { (Ar_5f_6) Mirá, está un poco incompleto y confuso ¿lo podés volver a hacer? Corregile las } \\
\text { cosas que te marqué, por favor, asi queda bien. }\end{array}$ \\
\hline 2$)$ & $\begin{array}{l}\text { (Ar_5f_13) Necesitaría que revise el informe mensual que presentó el otro día porque tiene } \\
\text { algunos errores. Va a tener que rehacerlo. }\end{array}$ \\
\hline 3$)$ & $\begin{array}{l}\left(\mathrm{Ar} 5 \mathrm{~m} \_8\right) \text { Mirá Fulano (en) este informe hubo un pequeño error, lo podrías hacer de nuevo. } \\
\text { Gracias. }\end{array}$ \\
\hline 4$)$ & \begin{tabular}{l}
$\left(\mathrm{Ar} 5 \mathrm{~m}_{-} 10\right)$ Debés rehacer el informe ya (que) tiene algunos errores que debés revisar. \\
\hline
\end{tabular}
\end{tabular}

\section{São Paulo}

\begin{tabular}{|c|c|}
\hline 1) & (Br_5f_6) Bom necessito que você refaça o relatório, pois algumas coisas estão erradas. \\
\hline 2) & (Br_5f_9) Olha, acho que falta coisa nesse relatório. Você poderia fazê-lo de novo? \\
\hline 3) & $\begin{array}{l}\text { (Br_5f_14) Oi, sabe aquele relatório mensal que você fez... vai ter que refazer pois tem } \\
\text { algumas coisas que não estão boas. }\end{array}$ \\
\hline 4) & (Br_5m_3) Por favor poderia refazer o relatório. Algumas partes precisam ser corrigidas. \\
\hline 5) & $\begin{array}{l}\text { (Br_5m_13) Podemos conversar? O último relatório está com alguns erros e é necessário } \\
\text { refazê-lo. }\end{array}$ \\
\hline
\end{tabular}

Ainda que estes modificadores não alteram o ato ilocucionário, atuam sobre o relatório mal elaborado (algunos errores, algumas coisas, etc.) podendo diminuir o quantum do dever de refazer. 
c) Eufemismos + Modificadores externos: quantificadores minimizadores, aproximativos ou difusores significativos proposicionais ou extraproposicionais

Uma característica encontrada na atenuação dos pedidos foi a combinação de duas táticas para mitigar a força ilocucionária: o emprego de eufemismos no verbo performativo e a limitação do que está sendo solicitado. Assim, por exemplo, rehacerlo / refazé-lo, que trazem em si a ideia de totalidade, tornam-se em alguns enunciados (Ar_5f_1) [...] podés cambiarlo (eufemismo) un poco (modificador externo minimizador), e (Br_5f_2) alguns pontos (modificador externo minimizador) [...] poderiam ser reescritos (eufemismo).

\section{Córdoba}

\begin{tabular}{|l|l|}
\hline 1) & $\begin{array}{l}\text { (Ar_5f_1) Disculpame, el informe que me entregaste no es el más adecuado según las } \\
\text { reglas de la empresa. Fijate si podés cambiarlo (eufemismo) un poco (modificador externo } \\
\text { minimizador) siguiendo las siguientes pautas. }\end{array}$ \\
\hline 2) & $\begin{array}{l}\text { (Ar_5f_3) El informe que me enviaste hay que revisarlo (eufemismo) porque no está del todo } \\
\text { bien (modificador externo aproximativo). Si tenés un tiempo podés venir a mi oficina así lo } \\
\text { revisamos. }\end{array}$ \\
\hline 3$)$ & $\begin{array}{l}\text { (Ar_5f_8) Disculpame Fulano pero voy a tener que pedirte que reveas (eufemismo) un } \\
\text { poquito (modificador externo minimizador + modificador morfológico interno: diminutivo) el } \\
\text { informe. Me parece que tiene algunas cosas (modificador externo minimizador) que están mal } \\
\text { ynecesito que las corrijas. }\end{array}$ \\
\hline 4$)$ & $\begin{array}{l}\text { (Ar_5m_5) Disculpe, me parece que hay algunos asuntos (modificador externo minimizador) } \\
\text { que necesitan revisión (eufemismo) en tu informe. }\end{array}$ \\
\hline
\end{tabular}

\section{São Paulo}

\begin{tabular}{|c|c|}
\hline 1) & $\begin{array}{l}\text { (Br_5f_2) Anotei alguns pontos (modificador externo minimizador) no seu relatório que } \\
\text { poderiam ser reescritos (eufemismo). Vou te mostrar e explico o porquê. }\end{array}$ \\
\hline 2) & $\begin{array}{l}\text { (Br_5f_5) Identifiquei alguns pontos (modificador externo minimizador) que precisam ser } \\
\text { melhorados/modificados (eufemismo) para ficar mais claro. }\end{array}$ \\
\hline 3) & $\begin{array}{l}\text { (Br_5f_11) Tem alguns pontos (modificador externo minimizador) neste relatório que você } \\
\text { poderia revisar (eufemismo). Eu anotei algumas coisas, dê uma olhada e depois me diga o } \\
\text { que achou. }\end{array}$ \\
\hline 4) & $\begin{array}{l}\text { (Br_5m_7) Você precisa prestar mais atenção ao fazer o relatório portanto passe a limpo } \\
\text { (eufemismo) e considere alguns pontos (modificador externo minimizador) que passaram } \\
\text { desapercebidamente. }\end{array}$ \\
\hline 5) & $\begin{array}{l}\text { (Br_5m_9) Fulano, encontrei alguns trechos (modificador externo minimizador) no } \\
\text { relatório que receio que precisariam ser reescritos (eufemismo). Você poderia dar uma } \\
\text { olhada, por favor? }\end{array}$ \\
\hline
\end{tabular}


Um primeiro dado que podemos ver é o emprego do futuro de pretérito no corpus de São Paulo, em 3 dos 5 enunciados: (Br_5f_2) poderiam ser reescritos; (Br_5f_11) que você poderia revisar; e (Br_5m_9) que receio que precisariam ser reescritos. O emprego deste tempo verbal se dá, precisamente, junto com os verbos performativos mais "diretos", como reescrever (2 oportunidades) e revisar. Isto não acontece quando os alunos paulistanos empregam verbos mais "leves", como em (Br_5f_5) precisam ser melhorados/modificados. Neste caso preferiram uma estrutura generalizadora como a voz passiva, mas com verbo em presente de indicativo.

No corpus em espanhol também há fórmulas generalizadoras da obrigação, como em (Ar_5f_3) hay que revisarlo, ou com verbos em terceira pessoa do plural, como em (Ar_5m_5) [asuntos] que necesitan revisión, contudo, não há emprego do futuro de pretérito. Os verbos que expressam o ato ilocucionário, mais uma vez são mais diretos no corpus da cidade argentina: revisar (2 ocorrências) e rever. Mesmo o verbo cambiar [um poco], empregado em (Ar_5f_1), se completa com a fórmula diretiva siguiendo las siguientes pautas.

Esta diferença no emprego do futuro do pretérito é uma tendência em todo o corpus brasileiro, em especial nos enunciados desta questão, como veremos abaixo.

d) Usos modalizadores dos tempos verbais: Usos modais do tempo verbal futuro do pretérito por presente ou imperativo

\section{Córdoba}

\begin{tabular}{|c|c|}
\hline 1) & $\begin{array}{l}\text { (Ar_5f_2) Mirá, el informe mensual que hiciste tiene muchos errores. Me di cuenta a medida } \\
\text { que lo leía. Te pediría si por favor podrías revisar los datos y hacer de nuevo el informe, asi } \\
\text { es un fiel reflejo de la realidad. }\end{array}$ \\
\hline 2) & $\begin{array}{l}\text { (Ar_5f_9) El trabajo es interesante pero me gustaría que lo reveas y corrijas los errores que } \\
\text { tiene. }\end{array}$ \\
\hline 3) & (Ar_5f_11) El informe tiene muchos errores ¿podrías rehacerlo por favor? \\
\hline 4) & $\begin{array}{l}\text { (Ar_5f_13) Necesitaría que revise el informe mensual que presentó el otro día porque tiene } \\
\text { algunos errores. Va a tener que rehacerlo. }\end{array}$ \\
\hline 5) & $\begin{array}{l}\text { (Ar_5f_18) Pedrito, ¿tendrás unos minutos para que revisemos en informe? Creo que } \\
\text { tendríamos que rehacerlo... }\end{array}$ \\
\hline 6) & (Ar_5m_4) Me parece que hay que revisar en informe de este mes ¿podrías rehacerlo? \\
\hline 7) & (Ar_5m_6) Juan, lo que te pedí no me convence ¿podrías volver a hacerlo? \\
\hline 8) & $\begin{array}{l}\text { (Ar_5m_8) Mirá Fulano (en) este informe hubo un pequeño error, lo podrías hacer de nuevo. } \\
\text { Gracias. }\end{array}$ \\
\hline
\end{tabular}




\section{São Paulo}

\begin{tabular}{|c|c|}
\hline 1) & $\begin{array}{l}\text { (Br_5f_1) Por favor, gostaria que você passasse a limpo o seu relatório pois precisa estar } \\
\text { caprichado. }\end{array}$ \\
\hline 2) & $\begin{array}{l}\text { (Br_5f_2) Anotei alguns pontos no seu relatório que poderiam ser reescritos. Vou te } \\
\text { mostrar e explico o porquê. }\end{array}$ \\
\hline 3) & $\begin{array}{l}\text { (Br_5f_4) Você teria condições de refazer este relatório? Acredito que seja capaz de algo } \\
\text { melhor. }\end{array}$ \\
\hline 4) & $\begin{array}{l}\text { (Br_5f_7) Analisei seu relatório e encontrei algumas objeções. Gostaria que você } \\
\text { melhorasse seu discurso de uma forma mais clara. Você pode por favor refazer. Muito } \\
\text { obrigada. }\end{array}$ \\
\hline 5) & $\begin{array}{l}\text { (Br_5f_11) Tem alguns pontos neste relatório que você poderia revisar. Eu anotei algumas } \\
\text { coisas, dê uma olhada e depois me diga o que achou. }\end{array}$ \\
\hline 6) & $\begin{array}{l}\text { (Br_5f_12) Esse relatório não está bem escrito. Teria como você arrumá-lo, por favor? É } \\
\text { importante. }\end{array}$ \\
\hline 7) & $\begin{array}{l}\text { (Br_5f_13) Você poderia refazer o relatório mensal? Há erros que não podem ser vistos } \\
\text { pelo gerente. }\end{array}$ \\
\hline 8) & (Br_5m_3) Por favor poderia refazer o relatório. Algumas partes precisam ser corrigidas. \\
\hline 9) & (Br_5m_8) Gostaria que você refizesse o relatório. \\
\hline 10) & $\begin{array}{l}\text { (Br_5m_9) Fulano, encontrei alguns trechos no relatório que receio que precisariam ser } \\
\text { reescritos. Você poderia dar uma olhada, por favor? }\end{array}$ \\
\hline 11) & (Br_5m_11) O relatório está mal feito, você poderia fazer, por favor? \\
\hline 12) & $\begin{array}{l}\text { (Br_5m_14) Gostaria de obter mais detalhes sobre o seu relatório. Poderia fazer do jeito.. } \\
\text { para tornar mais fácil? }\end{array}$ \\
\hline
\end{tabular}

Como havíamos antecipado o primeiro a destacar é, novamente, a clara superioridade do uso desta estratégia por parte dos alunos da universidade paulistana. A tabela a seguir ajudará na compreensão desta diferença.

\begin{tabular}{|c|c|c|}
\hline & Córdoba: 30 enunciados & São Paulo: 28 enunciados \\
\hline Futuro do pretérito & 8 ocorrências $=26 \%$ & 12 ocorrências $=42 \%$ \\
\hline
\end{tabular}

Tabela 1. Comparação do emprego de futuro do pretérito.

Outro ponto que se destaca é o emprego, quase ritualizado por parte dos informantes de Córdoba, deste tempo verbal com o verbo performativo refazer (e suas variantes com igual valor semântico) em sete dos oito enunciados. Só num enunciado (Ar_5f_9) aparece este tempo verbal com os verbos rever e corregir, cuja força ilocucionária não dista muito de refazer. Quanto a esta questão, no corpus dos alunos brasileiros, o emprego deste tempo verbal mais o verbo refazer (e equivalentes) aparece só na metade dos enunciados descritos. 
Todo isto contribui, certamente, à constatação de enunciados mais atenuados, por parte dos brasileiros, e mais diretos, por parte dos argentinos.

e) Uso de formas de tratamento e fórmulas apelativas

Conforme Albelda et alii (2014) as formas de tratamento e apelativas podem ser usadas para minimizar o expressado porque mostram aproximação com o ouvinte e podem servir para procurar o acordo ou o consenso ou a minimização do desacordo, como acontece nos casos abaixo:

\begin{tabular}{|c|c|}
\hline Córdoba: 12 casos & São Paulo: 9 casos \\
\hline $\begin{array}{l}\text { (Ar_5f_2) Mirá, el informe... } \\
\text { (Ar_5f_4) Mirá, el trabajo... } \\
\text { (Ar_5f_5) Mirá, vos sabes que... } \\
\text { (Ar_5f_6) Mirá, está un poco... } \\
\text { (Ar_5f_12) Mirá, me parece que... } \\
\text { (Ar_5f_15) Mirá el informe... } \\
\text { (Ar_5f_18) Pedrito, ¿tendrás unos... } \\
\text { (Ar_5f_19) Che, disculpame pero... } \\
\text { (Ar_5f_20) María, vení... creo que... } \\
\text { (Ar_5m_3) Escúcheme, su informe... } \\
\text { (Ar_5m_6) Juan, lo que te pedí... } \\
\text { (Ar_5m 8) Mirá Fulano (en) este informe... }\end{array}$ & $\begin{array}{l}\text { (Br_5f_6) Bom necessito que... } \\
\left(\mathrm{Br} 5 \mathrm{f} \_8\right) \text { Gente, vamos tentar... } \\
\left(\mathrm{Br} 55 \mathrm{f} \_9\right) \text { Olha, acho que... } \\
\left(\mathrm{Br} 55 \mathrm{f} \_14\right) \text { Oi, sabe aquele relatório... } \\
\left(\mathrm{Br} 55 \mathrm{~m} \_1\right) \text { Olha, não sei se há problemas... } \\
\left(\mathrm{Br} 5 \mathrm{~m} \_5\right) \text { Olha, entendo que... } \\
\left(\mathrm{Br} 5 \mathrm{~m} \_9\right) \text { Fulano, encontrei... } \\
\left(\mathrm{Br} 5 \mathrm{~m} \_10\right) \text { João, meu querido, o relatório... } \\
\left(\mathrm{Br} 55 \mathrm{~m} \_12\right) \text { Fulano, infelizmente... }\end{array}$ \\
\hline
\end{tabular}

As fórmulas apelativas Mirá (7 ocorrências), Escúcheme (1 ocorrência) e Olha (3 ocorrências) antecipam e colocam de forma objetiva que na sequência do enunciado haverá possíveis desacordos não desejados pelo falante. Inclusive estas fórmulas apelativas aparecem em vários casos combinadas com outras estratégias como formas de limitação do opinião própria como em (Ar_5f_12) Mirá, me parece que... (Br_5f_9) Olha, acho que... (Br_5m_5) Olha, entendo que... e ( $\left.\overline{\mathrm{Br}} 5 \mathrm{~m} \_1\right)$ Olha, não sei se há problemas...; e expressão de pesar, como em (Br_5m_12) Fulano, infelizmente...

As fórmulas de tratamento também podem combinar-se com outras estratégias de mitigação, como em (Ar_5f_18) Pedrito, ¿tendrás unos... (Usos modalizadores dos tempos verbais: Emprego do futuro em lugar do presente de indicativo); (Ar_5f_19) Che, disculpame pero... (Expressões de desculpas) (Ar_5f_20) María, vení... creo que... (construções verbais e partículas discursivas que expressam fingimento de incerteza); e (Br_5f_8) Gente, vamos tentar... (impessoalização mediante emprego de um nós inclusivo).

Percebemos, pela análise dos elementos desta questão, que ambas as comunidades de fala empregam estratégias de atenuação em larga escala. Todavia, os informantes de São Paulo fazem uso desses recursos em número maior e, por vezes, qualitativamente mais acentuado (variações sintagmáticas e paradigmáticas), como acontece nos casos do emprego das fórmulas eufemísticas (emprego de formas mais "brandas" que as dos cordobeses) e do uso do futuro do pretérito; conseguem, assim, um grau maior de atenuação que seus pares de Córdoba. Desta forma é lícito concluir que, de acordo com os conceitos de sociedades 
de aproximação ou distanciamento (Briz 2014: 89), os universitários paulistanos estão mais perto desta última que os cordobeses uma vez que, como aponta Albelda, precisam atenuar os enunciados para vencer a distância que os separa do outro (2008).

\subsection{Interpretação dos enunciados da questão 5 feita pelos alunos de Córdoba}

Nesta questão novamente o contexto, segundo explica Kerbrat-Orecchioni (2005), influencia diretamente no entendimento do ato ilocucionário. No ambiente de trabalho e na situação de ter apresentado um relatório ao chefe, toda manifestação dele que se refira ao informe que não seja uma parabenização, usualmente se interpreta como um pedido de reformulação. Tendo isto em conta, foi apresentada aos cordobeses a seguinte escala interpretativa do quanto eles entendiam que deveriam modificar do texto apresentado:

4) El jefe de departamento de la empresa en la que trabajás habla contigo acerca del informe mensual que hiciste y te dice lo siguiente:

(Enunciado do aluno de São Paulo. Por exemplo: O relatório está mal feito, você poderia fazer, por favor?)

De acuerdo con lo que se te solicita:

$\square$ Reharías totalmente el trabajo.

Lo reformarías en un $50 \%$.

Le cambiarías pocas cosas (un 30\%).

$\square$ Lo retocarías un poco.

Sobre um total de 30 enunciados, 9 informantes de Córdoba os interpretaram como um pedido de refazer totalmente o trabalho; 8 entenderam que deviam refazer $50 \%$ dele; 7 interpretaram que tinham que modificar poucas coisas e para os restantes 6 o pedido significava retocar um роисо o relatório, conforme o gráfico a seguir:

\section{Interpretação da questão 5}

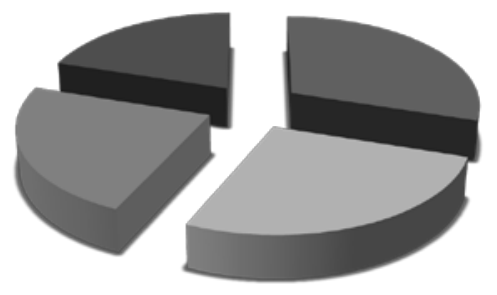

- $30 \%$ Reharías totalmente el trabajo.

$27 \%$ Lo reformaría em um $50 \%$.

- $23 \%$ Le cambiaría pocas cosas (menos de $30 \%$ ).

- $20 \%$ Lo retocarías um poco.

Gráfico 1. Interpretação dos informantes de Córdoba.

É oportuno lembrar que nas instruções originais dos questionários se solicitava aos universitários paulistanos e cordobeses que expressassem, quanto ao relatório, o pedido de refazê-lo /rehacerlo. Mutantis mutandi, entende-se que o ato ilocucionário que deviam trans- 
mitir era refazer o trabalho totalmente ou numa proporção importante. Pelo que observamos no gráfico, apenas $57 \%$ dos informantes de Córdoba conseguiram ter este entendimento enquanto um alto percentual deles (43\%) consideraram as exortações nas mínimas possibilidades. Mais ainda, se consideramos que a diferença entre os que interpretaram o pedido como refazer em $100 \%$ e os que só o retocariam um pouco é de somente $50 \%$ (9 ocorrências no primeiro dos extremos da gradação e 6 no outro) concluímos que é possível que existam problemas de intercompreensão entre paulistanos e cordobeses, em virtude do alto número de aproximativos e o emprego de eufemismos nos enunciados realizados pelos primeiros.

Outro ponto a destacar, comum a todas as questões, ainda que não se percebam diferenças substanciais quanto ao número e tipo de estratégias atenuadoras, é a ocorrência, na formulação dos enunciados dos cordobeses, de muitas marcas de coloquialidade em comparação com os paulistanos, tais como: (Ar_6m_20) No me digas! No te da asco! [...] Me quiero matar; (Ar_6m_5), etc. Por outro lado, apontamos marcas de formalidade no corpus dos paulistanos, como a escolha do verbo comparecer em lugar de ir/assistir, mais naturais entre amigos/as, em 4 oportunidades.

\section{CONSIDERAÇÕES FINAIS}

O objetivo do estudo intercultural realizado foi comparar os aspectos pragmáticos, em especial o emprego de procedimentos linguísticos de atenuação, na produção de atos de fala não corteses, atos diretivos e respostas não preferidas, por estudantes universitários das cidades de São Paulo (Brasil) e Córdoba (Argentina); também analisamos as possíveis diferenças nas interpretações que realizaram os estudantes da cidade argentina dos enunciados formulados pelos paulistanos.

Destacamos a importância da abordagem pragmática, tanto na produção de enunciados como na interpretação, uma vez que os possíveis problemas na compreensão intra e intercultural não se reduzem só a questões sintático-semânticas. Como já explicava Goffman (2011: 21), se uma pessoa quiser empregar seu repertório de práticas [...] obviamente ela deve, em primeiro lugar, ter consciência das interpretações que os outros podem ter colocado sobre os seus atos, e as "interpretações que ela talvez deva colocar sobre os deles". Todavia, para isso, deve-se ter conhecimento dos implícitos culturais da comunidade no qual se desenvolvem já que, conforme diz Charadeau (2012: 18), todos os intercâmbios de linguagem, desde a situação conversacional mais informal "até os intercâmbios delimitados institucionalmente [...] estão socialmente delimitados", por este motivo, tanto a emissão quanto a compressão de um enunciado estão atravessadas pelas pautas culturais dos interactantes, pela sua forma de ver e entender o mundo.

Embora neste artigo não seja possível tratar de todas as questões da pesquisa, foi possível apontar, como característica comum a todas as questões, que os enunciados, comparativamente, podem variar tanto no número de estratégias de atenuação (variação sintagmática), como ter diferenças significativas no emprego de formas mais atenuadoras (variação paradigmática). Como exemplo da primeira das variações, vejamos os seguintes enunciados, extraídos da questão 1, que guardam certo paralelismo: (Br_1f_7) Por gentileza você poderia ficar responsável por este parágrafo ou tirar xerox? (petição formulada com certa indiretividade + uso modal do tempo verbal futuro do pretérito por imperativo) Precisamos muito de sua colaboração (emprego de eufemismo: colaborar), sua participação 
é muito importante pois somos uma equipe (justificação do pedido apelando à pertença ao grupo + ato agradador da imagem do interlocutor: sua participação é muito importante) e (Ar_1f_12) Ya que somos un grupo (justificação do pedido apelando à pertença ao grupo) me gustaría que trabajaras al igual que todos (petição formulada com certa indiretividade + uso modal do tempo verbal futuro do pretérito por imperativo), y que trates de preocuparte un poco más. E, até quando empregados os mesmos procedimentos linguísticos atenuadores, por exemplo, o uso de eufemismos, ou a indiretividade, os falantes paulistanos conseguem efeitos mais mitigadores que os cordobeses. Assim, a fim de ilustrar essa regularidade, por exemplo, no uso de fórmulas de tratamento houve um elevado uso do vocativo Che por parte dos estudantes de Córdoba, enquanto os paulistanos empregaram formas mais amenas, como Minha colega; Amiga; Oi, tudo bem?; Então; e Caro amigo, etc.

Os resultados desta investigação apontam regularidades significativas que nos permitem afirmar que, sob a ótica do continuum em cujos extremos estão as sociedades de proximidade e de distanciamento, podemos explicar o comportamento dos cordobeses como próprio das primeiras, pelo maior relaxamento linguístico decorrente do menor emprego de atenuação e do estilo mais coloquial e direto de seus enunciados. Para reforçar tal conclusão, achamos oportuno lembrar que o maior ou menor número de atenuadores empregados e seu diverso grau de mitigação numa situação comunicativa refletirá a relação de mais proximidade ou distância, de mais igualdade ou desigualdade social e funcional entre os interlocutores (Albelda 2008: 99).

Por sua vez, o maior emprego de atenuação, muitas vezes estabelecido pelo uso de alternativas mais atenuadoras nas mesmas estratégias que os cordobeses, e a maior formalidade e indiretividade de seus enunciados, faz com que os paulistanos se coloquem mais perto das sociedades de distanciamento com relação aos cordobeses.

Quanto à interpretação das exortações dos paulistanos realizadas pelos cordobeses, percebemos problemas de entendimento, não só no sentido do ato de fala, muitas vezes determinado pelo contexto, mas também no quantum do que foi solicitado. Assim, na questão 5, frente ao enunciado solicitando refazer o relatório, $23 \%$ dos cordobeses entendeu que devia modificar poucas coisas e $20 \%$ só retocá-lo, mostrando que os procedimentos de atenuação interferiram na compreensão. $\mathrm{O}$ mesmo fenômeno de incompreensão ocorreu na questão 1 na qual o pedido de fazer a parte dele no trabalho acadêmico foi interpretado como um pedido de colaboração em $38 \%$ dos casos e $15 \%$ entendeu que se tratava de um simples chamado de atenção.

Este fenômeno não se limitou aos casos de enunciados exortativos, igualmente houve dificuldades para entender os atos assertivos de rejeição à pedidos (respostas não preferidas). Na questão 3, negativa a emprestar um livro a um professor, $39 \%$ dos alunos de Córdoba interpretou que os enunciados significavam um sim empresta (7\%) e talvez empreste (32 \%). E, na questão 7, novamente percebemos dificuldades na interpretação uma vez que a negativa a trabalhar no feriado, foi compreendida como vai trabalhar e talvez vá trabalhar em $35 \%$ das oportunidades. Pode-se apreciar que há certa tendência a considerar os atos de fala que expressam negação como comissivos, ou seja, tomar um não vou fazer por um faço sim ou talvez faça, devido à combinação de maior emprego de procedimentos atenuadores e a maior grau atenuador dos procedimentos empregados.

Estes problemas na intercompreensão entre os informantes das duas comunidades de fala podem ser explicados, em princípio, à luz das respostas à questão 9. Desta forma, ques- 
tionados quanto à escolha entre clareza e cortesia, $79 \%$ dos cordobeses se inclinou pela primeira das opções, enquanto $67 \%$ dos paulistanos optou pela segunda. Se, como observamos quando analisamos comparativamente os enunciados, os cordobeses são mais diretos na formulação deles, é lógico deduzir que também o serão quando postos a interpretá-los. Tem-se assim, uma questão que envolve, de um dos lados, a formulação mais cortês e menos clara por parte dos paulistanos e, do outro, a interpretação mais clara dos cordobeses, talvez desconsiderando questões de cortesia que não são próprias da sua cultura.

Para finalizar, acreditamos que os resultados desta pesquisa salientam a importância dos estudos interculturais porque contribuem para o melhor entendimento linguístico tanto da cultura própria como a cultura do outro porque, como aponta Charadeau (2012: 30), cada povo está imerso em seus usos e tem a tendência a crer que tais usos são universais. Aproveitamos aqui para ressaltar que os estudos pragmáticos interculturais tem por finalidade facilitar a compreensão para melhorar a comunicação, e não estabelecer comparações de superioridade ou inferioridade entre as culturas nem reforçar estereótipos.

\section{Referências bibliográficas}

Albelda Marco, Marta (2005c): "Discordancia entre atenuación/cortesía e intensificación/descortesía en conversaciones coloquiales". En Blas, J. L, Casanova, M., Velando, M. (eds.): Discurso y Sociedad. Contribuciones al estudio de la lengua en contexto social. Castellón: Servicio de publicaciones de la Universidad de Castellón, pp. 581-590.

Albelda, M. y A. Briz (2008). "Atenuantes en Chile y en España: distancia o acercamiento". En Briz, A., Hidalgo, A., Albelda, M., Contreras, J. y N. Hernández Flores (eds.). Cortesía y conversación: de lo escrito a lo oral. III Coloquio Internacional del Programa EDICE. Valencia-Estocolmo: EDICE.

Albelda, M. y A. Briz (2010). "Aspectos pragmáticos. Cortesía y atenuantes verbales en las dos orillas a través de muestras orales”. En M. Aleza Izquierdo y J. Enguita Utrilla (coords.). La lengua española en América: normas y usos actuales. Valencia: Universitat de València, PP. 237-260.

Albelda, M., Briz, A., Cestero, A., Kotwica, D. y C. Villalba (2014). "Ficha metodológica para el análisis pragmático de la atenuación en corpus discursivos del español”, Oralia, 17, pp. 7-62.

Briz, A. (2003). "La estrategia atenuadora en la conversación cotidiana española". En Actas del Primer Coloquio del Programa EDICE. Estocolmo: Universidad de Estocolmo, pp. 17-46.

Briz, A. (2004). "Cortesía verbal codificada y cortesía verbal interpretada en la Conversación”. En Bravo, D. y A. Briz (eds.). Pragmática sociocultural: estudios sobre el discurso de cortesía en español. Barcelona: Ariel, pp. 67-94.

Briz, A. (2007). "Para un análisis semántico, pragmático y sociopragmático de la cortesía atenuadora en España y América", LEA, 29/1, pp.5-40.

Briz, A. (2011). "La cortesía al hablar español". Ponencia presentada en COMPROFES. Congreso Mundial de Profesores de Español, Instituto Cervantes, 21-23 de noviembre: http:// comprofes.es/videocomunicaciones/clausura-\%C2\%ABla-cortes\%C3\%ADa-al-hablarespa $\%$ C3\%B1ol\%C2\%BB-y-conclusiones-del-comprofes (13/07/2013).

Briz, A. (2013). "Atenuadores: estratégias e táticas". Versão para o português: Luiz Antônio da Silva, Adriana Marcelle de Andrade, Ramiro Carlos Humberto Caggiano Blanco, Linha D'Água, 26, 281-314: http://www.revistas.usp.br/linhadagua/article/viewFile/64415/71564 (12/06/2014).

Briz, A. (2014). "La atenuación lingüística. Esbozo de una propuesta teórico-metodológica para su análisis". En Seara, I. R. Cortesia: olhares e (re) invenções. Chiado: Lisboa, pp. 83-172.

Brown, P. e S.C. Levinson, S. C. ([1978] 1987). Politeness. Some Universals in language Use. Cambridge: Cambridge University Press. 
Charadeau, P. (2012). "Problemas teóricos y metodológicos en los estudios de la oralidad aplicados a la cortesía: Aspectos lingüísticos, pragmáticos y discursivos”. Tradução: Julio Escamilla González. En Escamilla Morales, J., y Henry Vega, G. (eds.). Miradas multidisciplinares a los fenómenos de cortesía y descortesía en el mundo hispánico. Barranquilla: Universidad del Atlántico-Programa EDICE.

Charadeau, P. (2014). Linguagem e discurso:modos de organização. São Paulo: Contexto.

Escandell, M.V. (2004). "Competencia comunicativa, arquitectura cognitiva y disciplinas lingüísticas": http:/www.uned.es/dpto-leng-esp-y-ling-gral/Escandell/papers/Competencia,\%20arquitectura\%20y\%20disciplinas.pdf (10-06-2016).

Escandell, M.V. (2006). Introducción a la Pragmática. Barcelona: Ariel.

Goffman, E. (2011). Ritual da interação. Tradução: Fábio Rodrigues Ribeiro da Silva. Petrópolis, RJ: Vozes.

Haverkate, H. (1994). La cortesía verbal. Madrid: Gredos.

Haverkate, H. (2004). "El análisis de la cortesía comunicativa: categorización pragmalingüística de la cultura española”. En Bravo, D. y A. Briz (eds.). Pragmática sociocultural: estudios sobre el discurso de cortesía en español. Barcelona: Ariel, pp. 55-65.

Kerbrat-Orecchioni, C. (2005). "Os atos de linguagem no discurso. Teoria e funcionamento". Niteroi: EdUFF.

Kerbrat-Orecchioni, C. (2014). "Polidez e impolidez nos debates políticos televisivos: o caso dos debates entre dois turnos dos presidentes franceses". En Seara (org.) Cortesia: Olhares e (re) Invenções. Tradução: Ana Lúcia Tinoco Cabral. Lisboa: Chiado, pp. 47-82.

Levinson, S.C. (2007). Pragmática. São Paulo: Martins Fontes. 
